\title{
Investigating the Relationship between Tolerance of Ambiguity, Individual Characteristics and Listening Comprehension Ability among Iranian EFL Learners
}

\author{
Mahin Behresi ${ }^{1}$, Akbar Moulaei $^{1}$ \& Hossein Saadabadi Motlag ${ }^{1}$ \\ ${ }^{1}$ Department of English, Bushehr Branch, Islamic Azad University, Bushehr, Iran \\ Correspondence: Akbar Moulaei, Department of English, Bushehr Branch, Islamic Azad University, Bushehr, \\ Iran. E-mail: akbar.moulaei@chmail.ir
}

Received: October 28, 2016 Accepted: November 30, 2016 Online Published: December 2, 2016

doi:10.5539/ijel.v6n7p185 URL: http://dx.doi.org/10.5539/ijel.v6n7p185

\begin{abstract}
This study investigated the relationship between tolerance of ambiguity, individual differences and the listening comprehension ability of university students. The study was carried out at Azad University of Ahvaz, Foreign Languages Teaching Centre. It involved $150 \mathrm{MA}$ and BA students in the Faculty of language teaching center in university ( 78 females, 72 males) with the age range of 18-40. At first the Persian version of the questionnaire of tolerance of ambiguity provided by Ely (1995) was distributed among students of each class. Then the second questionnaire which was listening comprehension one was given to the students to collect the data on the base is of these hypotheses: $\mathrm{H}_{1}$ : There is no significant relationship between university students' tolerance of ambiguity and their listening comprehension ability. $\mathrm{HO}_{2}$ : Gender has no effect on tolerance of ambiguity of the students. $\mathrm{HO}_{3}$ : There is no significant relationship between age and student' tolerance of ambiguity. $\mathrm{H}_{4}$ : There is no significant relationship between academic level and students' tolerance of ambiguity Findings showed that there is a significant relationship between tolerance of ambiguity and listening comprehension. To answer second hypothesis, independent samples t-test was run. The results showed that gender did not have any significant impact on the students' ambiguity tolerance. The results one-way ANOVA depicted that there is significant difference between three different age groups (below 25, between 25-29, and above 29) $(p<0.05)$ in terms of tolerance of ambiguity $(F=4.291), p=0.015$. And at last, the results of the independent sample t-test showed that there is a significant difference between these two academic levels in tolerance of ambiguity.
\end{abstract}

Keywords: tolerance of ambiguity, individual differences, listening comprehension ability

\section{Introduction}

In recent years, a shift from an emphasis on the language teaching methodology to language learners and learner variables that affect language learning is the most important change in the teaching and learning a second/foreign language domain. Based on this, individual differences and learning styles have widely gained importance as they are considered to play a vital role in helping learners to have better achievement in language learning (Başöz, 2015). One of the most important learning styles is ambiguity tolerance. Brown (2000) defines it as "the degree to which you are cognitively willing to tolerate ideas and propositions that run counter to your own belief system or structure of knowledge". As Ely (1989) states, language learning is full of uncertainty and there is a considerable amount of ambiguity in learning a foreign language. If this ambiguity is not tolerated in a good way, language learners may get confused and stressed and feel uncomfortable when faceing some difficulties in this language (White, 1999). As a result, ambiguity tolerance can be regarded as a factor impeding or facilitating foreign language learning (Kamran, 2011). Listening comprehension is one of the skills that people need to develop to learn a second language because it is the main means through which learners get linguistic input. On the basis of Vandergrift' point of view (2007), in spite of the fact that listening comprehension lies at the heart of language learning, it is the least understood and last researched skill. In fact this skill is a complex process and yet necessary in the development of foreign language ability; but its importance in language acquisition has been recognized recently (Rost, 2002). Rastgar \& Mehrabikermani (2015) investigated the relationship among EFL learners' emotional intelligence, tolerance of ambiguity, and language learning strategies use. Tolerance of ambiguity was revealed to bear no significant relationship with the use of meta-cognitive and affective strategies, but its relationship with social strategies use was significantly negative. Moallemi Sharabiani (2011) investigated 
the degree of relationship between tolerance of ambiguity and guessing meaning of unknown words. The study revealed a significant relationship between these two variables. Anderson \& Lynch (1988) suggested that successful listening is "understanding is not something that happens because of what a speaker says: the listener has a crucial part in the process, by activating various types of knowledge, and by applying what he knows to what he hears and trying to understand what the speaker means" (p. 6). Abdollahian \& Fatemi (2013) have considered acculturation and proficiency level of learners as causal factors in foreign language Ambiguity Tolerance. A set-wise regression analysis revealed the two variables that contributed significantly to the prediction of foreign language ambiguity tolerance: preservation, and English language proficiency.

In spite of the significance of the listening skill in learning and assessing a foreign language, little has been done in order to determine and identify factors influencing it or correlating with the complex process of comprehension. Therefore, the present research aimed to understand how ambiguity tolerance of university students is related to their listening comprehension and three variables: gender, age and academic level in a foreign language. This study sought to answer the following research questions.

1) Is there any significant relationship between university students' tolerance of ambiguity and their listening comprehension ability?

2) Does gender have any effect on tolerance of ambiguity of the students?

3) Is there any significant relationship between age and students' tolerance of ambiguity?

4) Is there any significant relationship between academic level and students' tolerance of ambiguity?

Based on the mentioned questions posed by the researcher, the following null hypotheses were stated:

1) There is no significant relationship between university students' tolerance of ambiguity and their listening comprehension ability.

2) Gender has no effect on tolerance of ambiguity of the students.

3) There is no significant relationship between age and students' tolerance of ambiguity.

4) There is no significant relationship between academic level and students' tolerance of ambiguity.

\section{Research Method}

\subsection{Participants}

The study was carried out at Azad University of Ahvaz, Foreign Languages Teaching Centre. The data was collected in the autumn term of the 2015 academic year during normal class hours. It took about 50minutes to fill in the questionnaires. It involved MA and BA students in the Faculty of language teaching center in university. Participants of the present study were a total number of 150 students ( 78 females, 72 males), with the age range of $18-40$.

\subsection{Instrumentations}

In order to accomplish the purpose of the study, the following two instruments were utilized:

1) A tolerance of ambiguity questionnaire developed by Ely (1995) to find out the level of participants' ambiguity tolerance. It has 12 items and the responses are in Likert-scale format with a set of four responses including strongly agree, agree, disagree, and strongly disagree, sequentially assigning to values of 1,2,3, and 4 . As a result, the scores could range from 12 to 48, and the higher the mark, the more tolerant was the participant. Five minutes were given to the candidates to complete the questionnaire. This instrument is originally written in English but a Persian version of the quesstionnaire was used in the present study.

2) A listening Module from IELTS test. This test consists of four sections, each part with ten questions. The first two sections are concerned with social needs. The first section is a conversation between two speakers and the second section is a monologue. The final two sections are concerned with situations related to educational or training contexts. The third section is a conversation between up to four people and the four sections is a monologue. A variety of question types is used, including: multiple choices, matching, plan/map/diagram labeling, form completion, sentence completion, table completion, flow-chart completion, summary completion, sentence completion, and short-answer questions.

\subsection{Procedure}

In order to achieve the purpose of the research, the following procedure was carried out:

The respondents were given instructions on to fill in the questionnaires and were asked to complete them in approximately 50 minutes, bearing in mind that there were no right or wrong answers. It should also be noted 
that to enable the researcher to trace back the students during different stages of the study, all participants were assigned to an individual code which was same in their whole papers. At first the Persian version of the questionnaire of tolerance of ambiguity provided by Ely (1995) were distributed among students of each class. Students answered this questionnaire in 5 minutes. Then the second test which was listening comprehension one was given to the students. Candidates hear the recording once only and answer the questions as they listen. Ten minutes are allowed at the end for candidates to transfer their answers to an answer sheet. Each question in the listening part is worth one mark. Answering this part took 30 minutes. It is worth mentioning that in order to encourage the participants to answer with more care and honesty, they were assured that their responses to the instruments were used only for gathering information the purpose of the research and nobody but the researcher would have access to them.

\section{Results}

In order to test the hypotheses and come up with certain results, the researcher conducted a series of calculations and statistical routines that are elaborated comprehensively in this section. Both descriptive and inferential statistics were utilized in the process, details of which are presented below.

\subsection{Description of the Scaled Variables}

The Second Language Tolerance of Ambiguity Scale (SLTAS), and the listening module from IELTS were scored according protocols of the instruments' authors. Tables 1 and Table 2 present results of this analysis.

Table 1. Descriptive statistics of tolerance of ambiguity scale

\begin{tabular}{llllll}
\hline & N & Minimum & Maximum & Mean & Std. Deviation \\
\hline Tolerance of ambiguity & 150 & 15.00 & 43.00 & 29.4467 & 6.15628 \\
\hline Valid N (listwise) & 150 & & & & \\
\hline
\end{tabular}

The students had a mean of $29.4467(\mathrm{SD}=6.15628)$ for tolerance of ambiguity scale. Actual scores on this scale ranged from 15.00 to 43.00 .

Table 2. Descriptive statistics of the listening module

\begin{tabular}{lllllll}
\hline & N & Range & Minimum & Maximum & Mean & Std. Deviation \\
\hline Listening & 150 & 27.00 & 12.00 & 39.00 & 24.2000 & 6.41098 \\
\hline Valid N (listwise) & 150 & & & & \\
\hline
\end{tabular}

The students had a mean of $24.2000(\mathrm{SD}=6.41098)$ for the listening scale. Actual scores on this scale ranged from 12.00 to 30.00 . Following the descriptive statistics of this study, the three research hypotheses were investigated through correlational analysis of the data. In this section, first, each null hypothesis is tested; then, the results are provided and interpreted.

\section{$3.2 \mathrm{HO}_{1}$ : There is no significant relationship between university students' tolerance of ambiguity and their listening comprehension ability.}

To test the first hypothesis, a correlational analysis was run. As it is indicated in Table 3, the Pearson Product Correlation between the participants' tolerance of ambiguity and listening comprehension is found to be $(\mathrm{r}=.509)$ at significant level of $(0.000)$ which reveals a statistically significant positive correlation. The suggests that the more the participants are tolerant in ambiguous situations, the better scores in listening. Consequently, H01 is rejected at 0.01 level of significance and it is concluded that a statistically significant relationship exists between students' tolerance of ambiguity and the listening comprehension. 
Table 3. Correlation between autonomy and tolerance of ambiguity

\begin{tabular}{lll}
\hline & Tolerance of ambiguity & Listening comprehension \\
\hline Pearson Correlation Tolerance of ambiguity & 1 & $0.509^{* *}$ \\
Sig. (2-tailed) & & 0.000 \\
$\mathrm{~N}$ & 100 & 100 \\
\hline Pearson Correlation Listening comprehension & $0.509^{* *}$ & 1 \\
Sig. (2-tailed) & 0.000 & 100 \\
$\mathrm{~N}$ & 100 &
\end{tabular}

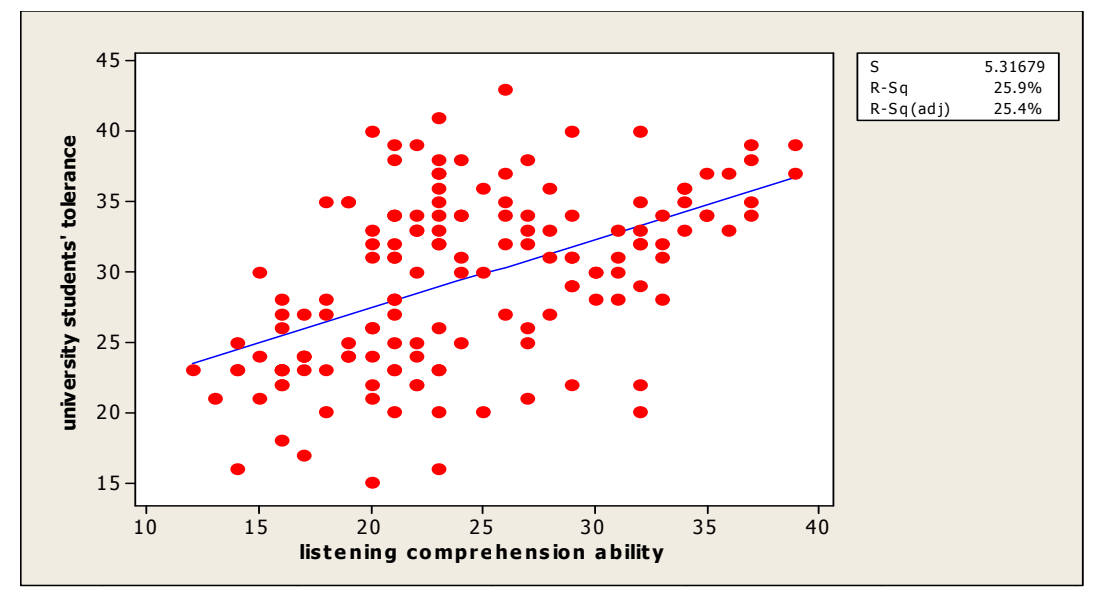

Figure 1. The correlation between tolerance of ambiguity and the listening test

On the basis of Figure 1, there is an acceptable correlation between the variables.

\section{$3.3 \mathrm{HO}_{2}$ : Gender has no effect on tolerance of ambiguity of the students.}

An independent samples t-test was performed so as to find out whether there is any significant gender-related difference in tolerance of ambiguity of the participants. The results are shown in the Table 4 and Figure 2 .

Table 4. Correlation between autonomy gender and tolerance of ambiguity

\begin{tabular}{lllllllll}
\hline & Gender & N & Mean & SD & MD & t & Df & Sig \\
\hline Ambiguity & male & 72 & 29.9444 & 6.23328 & .95726 & .951 & 148 & .343 \\
\hline Score & female & 78 & 28.9872 & 6.09768 & .95726 & .951 & 148 & .307 \\
\hline
\end{tabular}

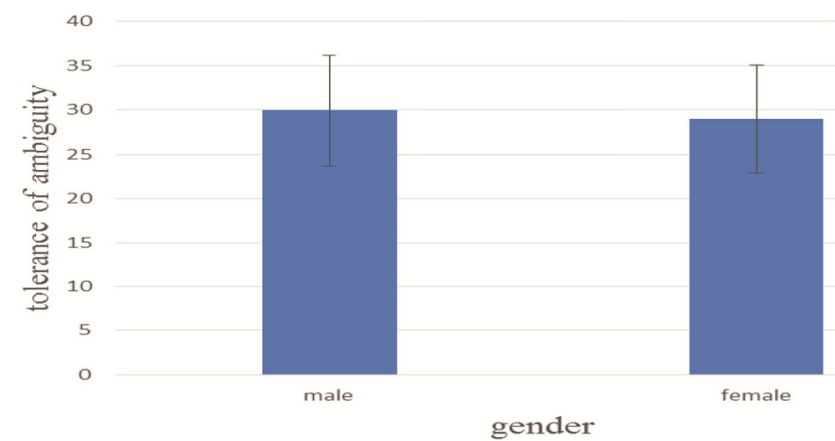

Figure 2. The effect of gender on tolerance of ambiguity

According to the table, there was no statistically significant difference between male $(\mathrm{M}=29,9444, \mathrm{SD}=$ $6.23328)$ and female participants' $(M=28.9872, \mathrm{SD}=6.09768), \mathrm{t}=.951, \mathrm{p}=.343$. That is to say, gender did not have any significant impact on the students' ambiguity tolerance. 


\section{4 $\mathrm{HO}_{3}$ : There is no significant relationship between age and student'tolerance of ambiguity.}

In this regard, the mean scores of the three age groups were compared through one-way analysis of variance (One-way ANOVA). The results of this study depicted that there is a significant difference between the three different age groups (below 25, between 25-29, and above 29) $(\mathrm{p}<0.05)$ in terms of tolerance of ambiguity $(\mathrm{F}=4.291), \mathrm{p}=0.015$. So the null hypothesis was safely rejected. Table 5, Table 6, Table 7 and also Figure 3 show the results of the one-way ANOVA about the effect of age on tolerance of ambiguity

Table 5. Descriptives of tolerance

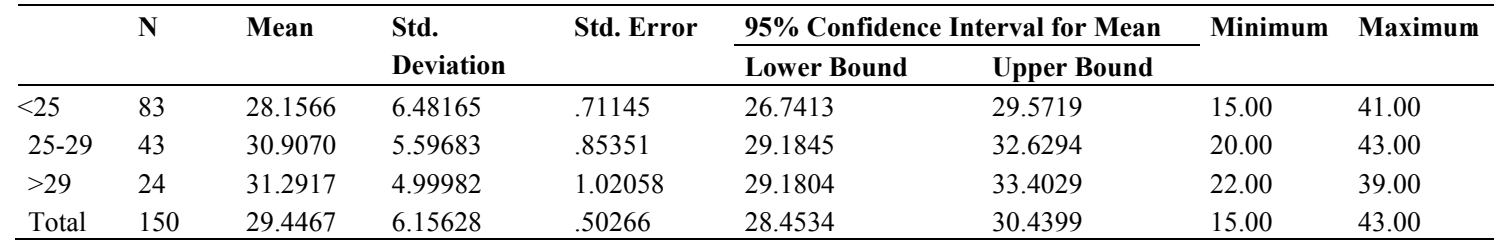

Table 6. ANOVA of tolerance

\begin{tabular}{llllll}
\hline & Sum of Squares & df & Mean Square & F & Sig. \\
\hline Between Groups & 311.523 & 2 & 155.762 & 4.291 & .015 \\
Within Groups & 5335.550 & 147 & 36.296 & & \\
Total & 5647.073 & 149 & & & \\
\hline
\end{tabular}

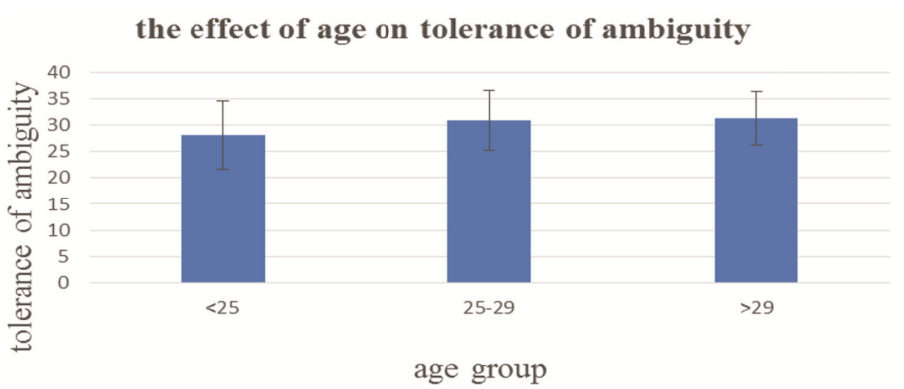

Figure 3. The effect of age on tolerance of ambiguity

To locate the difference among these groups the post-hoc Tokey was run. The result of the post-hoc showed that the level of tolerance of ambiguity was significantly different between the group which were below 25 and those between $25-29,(p=0.05)$ while the group that were above 29 showed more tolerance of ambiguity in comparison to the other groups but this difference was not significant. One of the reasons for this result is for few numbers of students in this age range. So in order to reach more clear results in this domain; it is necessary to do more studies (Table 7).

Table 7. Result of post-hoc

\begin{tabular}{|c|c|c|c|c|c|c|}
\hline \multirow[t]{2}{*}{ Age (I) } & \multirow[t]{2}{*}{ Age (J) } & \multirow[t]{2}{*}{ Mean Difference (I-J) } & \multirow[t]{2}{*}{ Std Error } & \multirow[t]{2}{*}{ Sig } & \multicolumn{2}{|c|}{$95 \%$ confidence Interval } \\
\hline & & & & & Lower Bound & Upper Bound \\
\hline \multirow{2}{*}{ Below25 } & $25-29$ & $-2.750 *$ & 1.132 & 0.043 & -5.430 & -0.070 \\
\hline & Above 29 & -3.135 & 1.396 & 0.067 & -6.441 & 0.171 \\
\hline \multirow{2}{*}{$25-29$} & Below 25 & $2.750 *$ & 1.132 & 0.043 & 0.070 & 5.431 \\
\hline & Above 29 & -0.385 & 1.535 & 0.966 & -4.019 & 3.250 \\
\hline \multirow{2}{*}{ Above 29} & Below 25 & $0.385^{*}$ & 1.396 & 0.067 & -0.171 & 6.441 \\
\hline & $25-29$ & 0.385 & 1.535 & 0.966 & -3.250 & 4.019 \\
\hline
\end{tabular}

3.5 $\mathrm{HO}_{4}$ : There is no significant relationship between academic level and tolerance of ambiguity.

An independent samples t-test was performed so as to find out whether there is any significant academic level related difference in tolerance of ambiguity of the participants. The results are shown in the Table 8 and Figure 4. 
Table 8 shows that there is a significant difference between these two levels on their tolerance of ambiguity.

Table 8. The effect of students' academic level on their tolerance of ambiguity

\begin{tabular}{lllllllll}
\hline & Academic level & N & Mean & SD & MD & t & df & Sig \\
\hline Ambiguity & MA & 50 & 31.5200 & 4.74337 & -3.1100 & -2.994 & 148 & 0.003 \\
Score & BA & 100 & 28.4100 & 6.53057 & -3.1100 & -2.994 & 148 & 0.003 \\
\hline
\end{tabular}

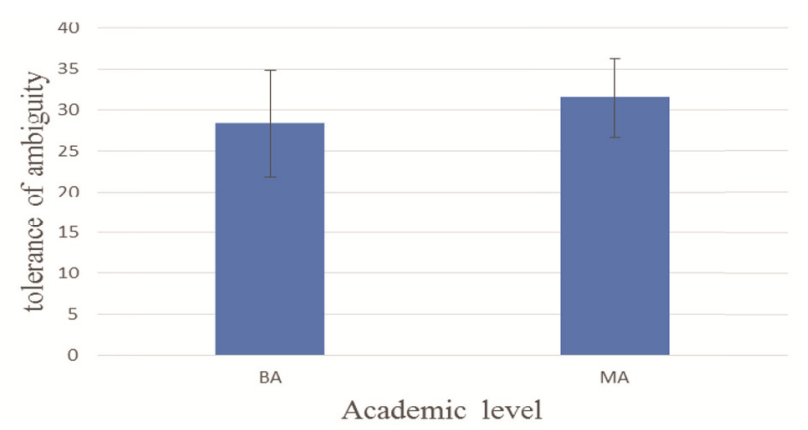

Figure 4. The effect of academic level on tolerance of ambiguity

\section{Conclusion and Discussion}

In order to explore any probable relationships among the variables of this research, the following 4 null hypotheses were posed to be tested:

1) There is no significant relationship between university students' tolerance of ambiguity and their listening comprehension ability.

2) Gender has no effect on tolerance of ambiguity of the students.

3) There is no significant relationship between age and student' tolerance of ambiguity.

4) There is no significant relationship between academic level and students' tolerance of ambiguity.

Considering theses hypotheses, this procedure was carried out to collect the required data. The questionnaires on tolerance of ambiguity and reading comprehension tests were distributed among 150 students as the main sample. With respect to the outcomes of the statistical analysis, the following results were obtained:

- The first null hypothesis $\left(\mathrm{HO}_{1}\right)$ was rejected, and it was concluded that a statistically significant relationship existed between students' tolerance of ambiguity and listening comprehension.

- The second null hypothesis $\left(\mathrm{H}_{2}\right)$ failed to be rejected, and it was revealed that there was no statistically significant difference among male and female students in tolerance of ambiguity.

- The third null hypothesis $\left(\mathrm{HO}_{3}\right)$ was rejected, and it was indicated that there was a statistically significant relationship between students' age and tolerance of ambiguity.

- The fourth null hypothesis $\left(\mathrm{HO}_{4}\right)$ was rejected, and it was indicated that there was a statistically significant relationship between students' academic level and tolerance of ambiguity.

So with respect to the results of this research regarding the questions posed in the study and based on the statistical analysis of the data, various degrees of correlation were found among the variables of this research. To come up with a clear idea and to provide pedagogical implications, discussion of these results would be of use. With respect to the findings of the current study in which a statistically positive and significant correlation was indicated between students' tolerance of ambiguity and their listening comprehension scores, it is that when ambiguity is tolerated, listening comprehension in an EFL context is enhanced, this correlation is statistically positive. The mentioned result is in line with Lou, Xu, Liu, \& Wei (2015) who found a positive relationship between tolerance of ambiguity and listening and EL-Koumy (2003), and Erten \& Topkaya (2009) whose correlational analysis revealed a strong relationship between tolerance of ambiguity and perceived success in reading in a foreign language. This result of the current study is also consistent with the results of the study by Abollahian (1999) who found a positive relationship between tolerance of ambiguity and receptive skills and Keshavar \& Assar (2011) who revealed a positive relationship between different levels of tolerance of ambiguity 
and reading comprehension. With regard to results of this study are in line with a study conducted by Atef-Vahid, Kashani, \& Haddadi (2011) which indicated that learners with higher levels of ambiguity tolerance were more likely to gain higher grades on cloze tests, and those with lower levels of ambiguity tolerance obtained lower scores on cloze tests. On the basis of Ely (1989) s definition of tolerance of ambiguity as the acceptance of uncertainties, this tolerance of ambiguity makes learners deal with new stimuli without frustration (Ellis, 1994). In this sense, students who have a good level of ambiguity tolerance, then, are expected to feel comfortable with learning a new language with its uncertainties and unknown structural and cultural norms (Erten \&Topkaya, 2009). On the basis of the results gender has not any significant effect on tolerance of ambiguity. However, few studies investigated gender differences in language learning style of ambiguity tolerance. Among the existing studies this study is in line with Kissau (2006) in his study on 490 French language learners (254 girls, 236 boys) in Ontario who reported no gender difference in tolerance of ambiguity and Saeedeh Karbalaee Kamran (2011). In contract, Sa'dabadi \& Sarkhosh (2014) and Maubach \& Morgan (2001) revealed that male students had a higher level of ambiguity tolerance compared to their female counterparts. Also the results regarding gender is opposite to Erten \& Topkaya (2009) who in their study on 173 Turkish university students (106 female, 67 males) reported a significant difference between male and female students in their tolerance of ambiguity with females exceeding males. With regard to third hypothesis, the findings show that there is a significant difference between different age groups. This finding is in line with DeForge \& Soba (1989) and Tatzel (1980), who found younger students to be more intolerant of ambiguity than older students (Weissenstein et al., 2014). However, in line with McLain (2008), the relationship between tolerances of ambiguity scores with age could lead to a different view: in fact with passing the time and increasing the ages of students individuals are exposed to greater ambiguity and are increasingly comfortable with ambiguity when they experience it. This interpretation leaves the door open to educational experiences designed to improve ambiguity tolerance (Arquero \& Tejero, 2009).

With respect to the findings of the study, a statistically significant and positive relationship was found between students' listening comprehension and their scores tolerance of ambiguity scale. Thus, if teachers can familiarize the students with the existence of this cognitive factor and make them recognize and realize its influence on their listening performance; students can accept the nature of ambiguous situations and try to overcome the debilitative effects of low ambiguity tolerance by consciously heightening their tolerance levels. They should continuously emphasize the fact that language learning is full of ambiguous dimensions and provide potentially suitable context for learners to find their ambiguity tolerance method and promote it towards academically recommended extent and directions.

Also, material developers, as providers of a large portion of the language learning setting, will benefit from the findings. They should insert ambiguity tolerance strengthening motives and techniques in appropriate parts of a course book for learners to take into account. In spite of fact that language learning is a multidimensional phenomenon, not only language teachers, but also students are required to play their role properly in order to facilitate and optimize this complicated process. Therefore, results of the current study have implications for students, encouraging them to become more tolerant in ambiguous situations in language learning context. At last, the findings of this study show that academic level makes a difference in learners' tolerance of ambiguity. This result is in contrast to Weissenstein et al. (2014). With respect to this fact that a mbiguity is the perception of inadequate information which is arising from certain characteristics of a situation (McLain, 2008), In a situation that demands evaluation or choice such as language learning contexts, ambiguity is threatening and put learners in a cognitive challenge in the form of desired, but absent or inaccessible information (Pich et al., 2002). Thus students with higher educational level access to more information in language so they can understand ambiguous situation better and make choices with predictable outcomes. Also with increasing the age of learners, they can have more educational experiences, and become more proficient in language learning so they experience less anxiety when experience ambiguous situation.

\section{References}

Abdollahian, G., \& Fatemi, A. Z. (2013). A correlational study of EFL learners' ambiguity tolerance and acculturation in receptive skills. International Journal of Language Learning and Applied Linguistics World (IJLLALW), 4(4), 613-628.

Arquero, J. L., \& Tejero, C. (2009). Niveles de Tolerancia a la Ambigüedad en Estudiantes Españoles de Contabilidad: Un Estudio Comparativo. Revista de Contabilidad, 12(1), 95. https://doi.org/10.1016/S1138-4891(09)70003-2

Atef-Vahid, S., Kashani, A. F., \& Haddadi, M. (2011). The relationship between level of ambiguity tolerance and cloze test performance of Iranian EFL learners. Linguistic and Literary Broad Research and Innovation, 
2(2), 149-169.

BAŞÖZ, T. (2015). Exploring the relationship between tolerance of ambiguity of EFL learners and their vocabulary knowledge. Journal of Language and Linguistic Studies, 11(2), 53-66.

Brown, H. D. (2000). Principles of language learning and teaching (4th ed.). New York: Pearson Education Company.

DeForge, B. R., \& Soba, 1. J. (1989). Intolerance of ambiguity in students entering medical school. Soc Sci Med, 28, 869-874. https://doi.org/10.1016/0277-9536(89)90117-2

El-Koumy, A. S. A. (2003). Differences in FL reading comprehension among high-, middle-, and low-ambiguity tolerance students. Education Resources Information Center (ERIC), USA. https://doi.org/10.2139/ssrn.2365143

Ellis, R. (1994). The study of second language acquisition. Oxford: Oxford University Press.

Ely, C. M. (1989). Tolerance of ambiguity and use of second language strategies. Foreign Language Annals, 22(5), 437-445. https://doi.org/10.1111/j.1944-9720.1989.tb02766.x

Ely, C. M. (1995). Tolerance of ambiguity and the teaching of ESL. In J. Reid (Ed.), Learning styles in the ESL/EFL classroom (pp. 87-95). Boston, MA: Heinle \& Heinle.

Erten, I. H., \& Topkaya, E. Z. (2009). Understanding tolerance of ambiguity of EFL learners in reading classes at tertiary level. Novitas-Royal, 3(1), 29-44.

Kamran, S. K. (2011). Effect of gender on ambiguity tolerance of Iranian English language learners. Journal of Education and Practice, 2(11), 5-10.

Keshavarz, M. H., \& Assar, M. (2009). Reading comprehension ability and meta-cognitive awareness of reading strategies among high, mid and low ambiguity tolerance EAP students. Iranian Journal ofApplied Linguistic Studies, 1(2), 71-108.

Kissau, S. (2006). Gender differences in motivation to learn French. Canadian Modern Language Review, 62(3), 401-422. https://doi.org/10.3138/cmlr.62.3.401

Lou, Y. G., Xu, P., Liu, H. L., \& Wei, X. X. (2015). A Study of the Correlation between Non-English- Majored Graduates' Scores of College English Test 6 and Tolerance of Ambiguity. Creative Education, 6, 2169-2173. http://dx.doi.org/10.4236/ce.2015.620221

Maubach, A. M., \& Morgan, C. (2001). The relationship between gender and learning styles amongst A level modern languages students. Language Learning Journal, 23(1), 41-47. https://doi.org/10.1080/09571730185200081

McLain, D. L. (2008). Evidence of the Properties of an Ambiguity Tolerance Measure (MSTATII). Psychological Reports. Article currently under review.

Pich, M. T., Loch, C. H., \& Meyer, A. D. (2002). On Uncertainty, Ambiguity, and Complexity in Project Management. Management Science, 48(8), 1008-1023. https://doi.org/10.1287/mnsc.48.8.1008.163

Rost, M. (2002). Teaching and researching listening. London, UK: Longman.

Sa'dabadi, N., \& Sarkhosh, M. (2014). The Relationship among Level of Ambiguity Tolerance and Cloze Test Performance of Iranian EFL Learners Across Gender. International Journal of Language Learning and Applied Linguistics World, 6(4), 340.

Tatzel, M. (1980). Tolerance for ambiguity in adult college students. Psychol Rep, 47, 377-378. https://doi.org/10.2466/pr0.1980.47.2.377

Tudor, I. (1996). Learner-centredness as language education (Vol. 279). Cambridge: Cambridge University Press.

Vandergrift, L. (2007). Recent developments in second and foreign language listening comprehension research. Language Teaching, 40, 191-210. https://doi.org/10.1017/S0261444807004338

Weissenstein, A., Ligges, S., Brouwer, B., Marschall, B., \& Friederichs, H. (2014). Measuring the ambiguity tolerance of medical students: a cross-sectional study from the first to sixth academic years. BMC Family Practice, 15, 2-6. https://doi.org/10.1186/1471-2296-15-6

White, C. (1999). Expectations and emergent beliefs of self-instructed language learners. System, 27, 443-457. http://dx.doi.org/10.1016/S0346-251X(99)00044-5 


\section{Copyrights}

Copyright for this article is retained by the author(s), with first publication rights granted to the journal.

This is an open-access article distributed under the terms and conditions of the Creative Commons Attribution license (http://creativecommons.org/licenses/by/4.0/). 